INVITED REVIEW

\title{
Cyclic Cushing's syndrome: a clinical challenge
}

\author{
J R Meinardi ${ }^{1,2}$, B H R Wolffenbuttel ${ }^{2}$ and R P F Dullaart ${ }^{2}$ \\ ${ }^{1}$ Department of Internal Medicine, Canisius Wilhelmina Ziekenhuis, PO Box 9015, 6500 GS Nijmegen, The Netherlands and ${ }^{2}$ Department of \\ Endocrinology, University Medical Centre Groningen, University of Groningen, PO Box 30001, 9700 RB Groningen, The Netherlands \\ (Correspondence should be addressed to: R P F Dullaart; Email: r.p.f.dullaart@int.umcg.nl)
}

\begin{abstract}
Cyclic Cushing's syndrome (CS) is a rare disorder, characterized by repeated episodes of cortisol excess interspersed by periods of normal cortisol secretion. The so-called cycles of hypercortisolism can occur regularly or irregularly with intercyclic phases ranging from days to years. To formally diagnose cyclic CS, three peaks and two troughs of cortisol production should be demonstrated. Our review of 65 reported cases demonstrates that cyclic CS originates in 54\% of cases from a pituitary corticotroph adenoma, in $26 \%$ from an ectopic ACTH-producing tumour and in about $11 \%$ from an adrenal tumour, the remainder being unclassified. The pathophysiology of cyclic CS is largely unknown. The majority of patients with cyclic CS have clinical signs of CS, which can be either fluctuating or permanent. In a minority of patients, clinical signs of CS are absent. The fluctuating clinical picture and discrepant biochemical findings make cyclic CS extremely hard to diagnose. Clinicians should therefore be aware of this clinical entity and actively search for it in all patients with suspected CS but normal biochemistry or vice versa. Frequent measurements of urinary cortisol or salivary cortisol levels are a reliable and convenient screening tool for suspected cyclic CS. Cortisol stimulation or suppression tests may give spurious results owing to spontaneous falls or rises in serum cortisol at the time of testing. When cyclic CS is biochemically confirmed, further imaging and laboratory studies are guided by the presence or absence of ACTH dependency. In cases of suspected ectopic ACTH production, specific biochemical testing for carcinoids or neuroendocrine tumours is required, including measurements of serotonin in platelets and/or urine, chromogranin A and calcitonin.
\end{abstract}

European Journal of Endocrinology 157 245-254

\section{Introduction}

In a small subgroup of patients with Cushing's syndrome (CS), cortisol secretion is only periodically increased. This phenomenon of intermittent hypercortisolism - also called cyclic CS - may be easily missed in clinical practice with consequential treatment delay. Searching English literature, we found 65 case reports of cyclic CS, which form the basis of the present review.

\section{Cortisol secretion patterns}

In healthy individuals, cortisol is secreted on a diurnal rhythm with peak cortisol concentrations early in the morning and a nadir around midnight (1). Cortisol secretion also follows ultradian (lasting $<24 \mathrm{~h}$ ) and infradian (lasting $>24 \mathrm{~h}$ ) rhythms, superimposed on the diurnal cycle (1-3). The ultradian rhythm consists of six to nine brief bursts of cortisol secretion followed by cessation of secretion in $\sim 3$-h cycles throughout a 24-h period $(1,2)$. These bursts of cortisol cluster during the second half of the sleep period and the subsequent morning waking time. The infradian rhythms are of low amplitude and last weeks to months (3). All these distinct rhythms are supposed to be primarily determined by the actions of corticotrophin releasing hormone (CRH) and adrenocorticotrophic hormone (ACTH).

With few exceptions, patients with CS classically lack the normal circadian rhythm (4). In patients with cyclic CS, hypercortisolism is present periodically. During the intercyclic phase, serum cortisol might be slightly elevated, normal or even subnormal. This phenomenon has first been reported as a distinct clinical entity by Bailey in 1971 (5), but in retrospect, this phenomenon had already been recognized earlier (6-8).

\section{Definitions and criteria of cyclic CS}

Generally accepted criteria to diagnose cyclic CS include three peaks and two troughs of cortisol production (9). Although these criteria apply for most patients, they might be hard to fulfil in others, particularly if the intercyclic phase is large. Different classifications and terms for cyclic CS are used. Shapiro et al. related the clinical expression to the pattern of 
cyclic cortisol overproduction in 44 patients with cyclic CS (10). They grouped CS cases in four categories:

Category 1 regular cyclic hormonogenesis with nonvariable clinical expression

Category 2 regular cyclic hormonogenesis with periodic clinical expression

Category 3 irregular cyclic hormonogenesis with corresponding clinical signs and symptoms

Category 4 irregular cyclic hormonogenesis with constant clinical manifestations

Based on this classification, different terms for cyclic CS have been used, including periodic hormonogenesis (category 1) (5) and intermittent CS (category 3) (11). Besides, several other descriptions have been used, such as periodic CS (12), intermittent hypercortisolism (13), cyclic hormonogenesis (14) and periodic CS (15). Irrespective of permanent or variable clinical expression, the cycle length of hypercortisolism is remarkably constant within one subject but can vary from days to months between individuals. In patients with irregular cortisol activity, the cycle frequency may vary from 10 times in 3 months to twice in 5 years. It is therefore clear that not all patients can be reliably classified according to the cortisol secretion pattern or clinical expression, particularly if the disease has a prolonged nature. In addition, such classification has no clinical consequence, since it does not influence the treatment. It thus seems appropriate to unify these different classifications into one clinical entity. In this article, we will use the term cyclic CS to describe both patients with regular as well as those with irregular hypersecretion of cortisol, irrespective of the variation in clinical expression.

\section{Prevalence}

The estimated annual incidence of Cushing's disease in the general population ranges from 0.1 to 1.0 per 100000 and that of other causes of CS is five to six times lower (16). Cyclic CS is considered to be far more rare. Its prevalence is likely to be underestimated, since cyclic CS is easily overlooked. Furthermore, previously reported spontaneous remissions of CS may in fact be the consequence of unrecognized cyclic hormonogenesis. Three small studies indicate that cyclic CS is indeed more common than expected. McCance et al. evaluated serum cortisol levels in 41 patients with Cushing's disease who underwent transsphenoidal surgery (17). Cyclic cortisol production appeared to be present in seven $(17 \%)$ of them. Streeten and co-workers determined the frequency of intermittent hypercortisolism in 31 patients with Cushing's disease after transsphenoidal surgical procedures, and demonstrated intermittent hypercortisolism in six subjects (19\%) (18). Atkinson et al. followed 14 patients with CS during 2 years by frequent cortisol measurements and documented cyclic hormonogenesis in five patients (36\%) (19). These data suggest that cyclic cortisol production is present in about $20-40 \%$ of patients with CS, which might only be detected by careful investigation of the cortisol secretion pattern.

Cyclic CS has also been reported in children, and is even common in the rare disorder of adrenocortical hyperplasia (20-22).

\section{Literature retrieval of cyclic CS cases}

In order to assess the spectrum of the clinical and laboratory characteristics of patients with cyclic CS, we evaluated all reported cases since 1960. For this purpose, a PubMed search was performed using the keywords 'cyclic', 'periodic', 'intermittent','Cushing' and 'hypercortisolism'. Furthermore, reference lists were manually checked for relevant articles.

Excluded were case reports published in medical journals with non-English abstracts or those missing essential clinical data required for analysis. Using this search 65 reported cases were identified that were suitable for further analysis $(5,7,9-15,20,21,23-67)$.

\section{Clinical characteristics}

All major causes of hypercortisolism can manifest in patients with cyclic CS. Table 1 shows the data of 65 patients with cyclic CS, divided according to the aetiology of cortisol excess. Cushing's disease was the underlying cause in 54\%, ectopic secretion of ACTH in $26 \%$, and primary adrenal CS in $11 \%$. In comparison, the corresponding prevalences of patients with CS in general are 68,12 , and $20 \%$ respectively (68). Thus, it appears that occurrence of ectopic ACTH syndrome is more frequent in patients with cyclic CS.

Carcinoids are the most frequently reported cause of patients with cyclic ectopic ACTH secretion. Of note, no cyclic CS due to small cell lung cancer has been reported, which is remarkable in view of the relatively high frequency of this malignancy in patients with ectopic ACTH production $(69,70)$. It is plausible that cyclic cortisol activity is difficult to demonstrate in such patients due to the rapidly progressive course of the disease.

As with classic hypercortisolism, cyclic CS is found more commonly among women than men, with a female to male ratio of 3:1 (Table 2). The disorder usually becomes manifest in the fifth decade, but may present from early infancy until older age (highest reported age at presentation being 72 years).

Ten children and adolescent patients (five boys and five girls), with an age ranging from 1 to 17 years, have been reported so far with cyclic CS. Two had Cushing's disease, two suffered from carcinoid tumour (one thymic carcinoid and one renal carcinoid) and three had bilateral pigmented micronodular adrenal hyperplasia. In the remaining three children, no classifying diagnosis could be made. These 
Table 1 Cases with cyclic Cushing's syndrome reported in the literature.

\begin{tabular}{llcc}
\hline Cause & & Number of cases $(n=65)$ & References \\
\hline Pituitary ACTH & & $35(54 \%)$ & $\left(9,10,11^{\mathrm{a}}, 13,14,23,24,25-44^{\mathrm{a}}\right)$ \\
Ectopic ACTH & Overall & $17(26 \%)$ & $(5121545-4951-5866)$ \\
& Thymic carcinoid & 6 & $(15,47,48,53,54,66)$ \\
& Bronchial carcinoid & 4 & $(5,45,46,55)$ \\
& Pancreatic carcinoid & 1 & $(51)$ \\
& Renal carcinoid & 1 & $(12)$ \\
& Gastric carcinoid & 1 & $(58)$ \\
& Epithelial thymoma & 1 & $(56)$ \\
Adrenal & Phaeochromocytoma & 1 & $(57)$ \\
& Occult & 2 & $(49,52)$ \\
& Overall & $7(11 \%)$ & $\left(7,10,20^{\mathrm{a}}, 21,59-61\right)$ \\
& Adenoma & 3 & $\left(10,60^{\mathrm{a}}, 61\right)$ \\
Unclassified & Pigmented nodular adrenocortical & 3 & $(20,21,59)$ \\
\hline
\end{tabular}

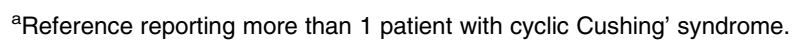

underlying causes are also found in children with classic CS, with a comparable frequency $(16,71)$.

Cyclic CS may present with only one typical feature of CS. The majority (95\%) of patients with cycling CS, however, have at least two features which are considered to be typical for CS (Table 2). Disorders such as glucose intolerance, mood disturbances, acne, hirsutism and amenorrhoea are present in a substantial proportion of patients. Mood disturbances may include severe depression, psychosis, neurosis, irritability, emotional lability or memory disturbances which often dominate the clinical picture. In case of mood disturbances, it has to be determined whether hypercortisolism is the cause (true cycling CS) or consequence (i.e. pseudo-CS; see further).

\section{Prognosis}

The life expectancy of patients with cyclic CS is unknown, because there are no well-designed cohort studies on this topic. From our clinical data, no reliable conclusions can be made, since they are likely to be influenced by selection and publication bias.

Patients with cyclic Cushing's disease who underwent neurosurgical intervention appear to have a high recurrence rate $(63 \%)$ and a low remission rate $(25 \%)$ (72), which is in line with a recurrence in 11 out of 21 patients $(52 \%)$ after neurosurgery in our current analysis. In comparison, a cure rate of $\sim 80 \%$ is usual in patients with non-cyclic Cushing's disease (68).

\section{Pathophysiology of cyclic CS}

The pathophysiology of cyclic CS is still largely unknown. It has been proposed that episodic haemorrhage or synchronic growth and death of ACTH- or cortisol-producing tumour cells may lead to periodic hypercortisolism (67). In support of this theory, necrosis has been found in removed corticotroph

Table 2 Clinical characteristics of patients with cyclic Cushing's syndrome. Data retrieved from 65 case reports.

\begin{tabular}{|c|c|c|c|c|}
\hline & Overall $^{\mathrm{a}}(n=65)$ & Pituitary $(n=35)$ & $\begin{array}{l}\text { Ectopic ACTH } \\
\quad(n=17)\end{array}$ & Adrenal $(n=7)$ \\
\hline Female sex, $n(\%)$ & $47(72)$ & $25(71)$ & $13(76)$ & $4(57)$ \\
\hline Age at diagnosis, median (range), years & $41(0-72)$ & $41(4-71)$ & $43(12-72)$ & $21(0-46)$ \\
\hline Cushing features $^{\mathrm{b}}, n(\%)$ & $61(94)$ & $32(91)$ & $17(100)$ & $6(86)$ \\
\hline \multicolumn{5}{|l|}{ Additional disorders, $n(\%)$} \\
\hline $\begin{array}{l}\text { Diabetes mellitus or } \\
\text { glucose intolerance }\end{array}$ & $25(38)$ & $12(34)$ & $8(47)$ & $1(14)$ \\
\hline Mood disorders & $15(23)$ & $6(17)$ & $3(18)$ & $2(29)$ \\
\hline Acne & $7(11)$ & $3(9)$ & $2(12)$ & $0(0)$ \\
\hline Hirsutism & $15(23)$ & $9(26)$ & $4(24)$ & $0(0)$ \\
\hline Amenorrhoea (\% of women) & $6(13)$ & $6(17)$ & $0(0)$ & $0(0)$ \\
\hline Cycle length, median (range), days & $21(3-510)$ & $18(0.5-510)$ & $30(4-180)$ & $35(14-60)$ \\
\hline Intercyclic phase, median (range), days & $30(1-2160)$ & $20(1-1642)$ & $35(1-2160)$ & $120(60-720)$ \\
\hline Survival, $\%$ of reported $(n / n)$ & $94(58 / 62)$ & $97(33 / 34)$ & $80(12 / 15)$ & $100(7 / 7)$ \\
\hline Follow-up, years, median (range) & $2.7(0.08-26)$ & $3(0.08-13)$ & $2.25(0.8-11)$ & $7(1-26)$ \\
\hline
\end{tabular}

ancluding cases with an uncertain origin of cyclic hypercortisolism.

${ }^{\mathrm{b}}$ Two or more of the following signs: hypertension, truncal obesity, buffalo hump, moon face, oedema, muscle weakness, striae. 
adenoma of patients with cyclic CS $(28,51,53)$, although others failed to find such necrotic areas in ACTH-secreting tumoural tissue (5). Cyclic Cushing's disease has been reported in association with a pituitary stone (44), the latter being thought to represent calcification of infarcted neoplastic tissue, in line with the proposed theory. Nevertheless, the strict regularity of cyclic cortisol secretion, observed in several patients with cyclic CS, is difficult to explain by fluctuating cell growth and death only. Another mechanism might be persistence of negative feedback control of tumoural ACTH secretion by cortisol in cyclic CS (54). A third theory regards only cyclic Cushing's disease and supposes a hypothalamic origin, with periodic changes in substances contributing to pituitary ACTH secretion being involved. These neurotransmitters include CRH, noradrenaline (NA), dopamine, acetylcholine and $\gamma$-aminobutyric acid (GABA). Some patients with cyclic Cushing's disease respond on sodium valproate, a GABA agonist, which inhibits CRH secretion without affecting pituitary ACTH secretion (35). So, this may imply an important pathogenetic role for CRH in cyclic Cushing's disease, although this mechanism has not been confirmed in another study (43). Changes in the central dopaminergic tone may also be responsible for cyclic Cushing's disease (73). Accordingly, patients with cyclic Cushing's disease may effectively respond to the dopamine agonist bromocriptine $(36,43)$. In rats, central NA inhibits ACTH secretion and inversely relates with plasma corticosterone (74). Considering that dopamine suppresses vasopressin (75), it is of interest that in one case both ACTH and vasopressin were found to be secreted in a cyclical pattern (64), illustrating a possible influence of an altered central dopaminergic system in the development of cyclic Cushing's disease. Furthermore, hypothalamic serotonin production might be involved in the development of cyclic Cushing's disease. It has been suggested that cyproheptadine, which has predominant antiserotonin effects on the hypothalamus, lowers hypercortisoluria (27) and might induce a clear reduction in magnitude and frequency of ACTH pulses in cyclic CS (42). Finally, in cyclic CS, simultaneous expression of both ghrelin and growth hormone secretagogue receptors has been documented in a bronchial carcinoid tumour that gave rise to ectopic ACTH expression. This might imply that ACTH secretion by this tumour is regulated in an autocrine or paracrine manner (46).

\section{Differential diagnosis of cyclic CS}

Diagnosing cyclic CS can be extremely difficult, and any aetiology of CS can manifest with periodic glucocorticoid hypersecretion. Furthermore, clinical manifestations vary widely intra- and interindividually and can even remain absent in some patients with cyclic CS. In the differential diagnosis, the following conditions should be considered: mild and subclinical CS, pseudo-Cushing's states, aberrant receptormediated CS, factitious CS and glucocorticoid resistance.

\section{Mild and subclinical CS}

Recommended initial screening studies for CS are assessment of urinary free cortisol excretion in at least three $24 \mathrm{~h}$ urine collections and the low-dose overnight dexamethasone suppression test $(76,77)$. However, no single test has optimal diagnostic accuracy. In case of strong clinical suspicion for CS but normal initial work up, clinical follow-up and repeated testing over time is warranted. This approach allows to determine progression of the clinical and biochemical abnormalities over time, and to demonstrate whether cortisol overproduction occurs in a periodic fashion. The combined $2 \mathrm{mg}$ dexamethasone-CRH test is accurate in differentiating between mild Cushing's disease and normal physiology (78) but has not been evaluated in cyclic CS. The role of late night salivary cortisol sampling as screening test for CS is not yet clear. The entity of subclinical CS, characterized by subclinical autonomous glucocorticoid hypersecretion, is mostly confined to incidentally discovered adrenal masses (79-81). Diagnostic criteria vary between studies. As with mild CS, follow-up is needed to determine whether progression to overt disease occurs.

\section{Pseudo-Cushing's states}

As reviewed elsewhere (77), pseudo-Cushing's state is characterized by a clinical picture resembling true CS together with biochemical abnormalities suggestive of hypercortisolism, which resolves after resolution of the underlying non-endocrine cause. Depression and alcohol abuse are important causes of a pseudo-Cushing's state. Recognizing that depression and alcohol abuse can cause reversible abnormalities in the hypothalamic-pituitary-adrenal axis is important for differentiating cyclic CS from these conditions. Urinary free cortisol excretion shows considerable overlap between patients with depression and CS (77). Depressed patients frequently demonstrate insufficient suppression of urinary and serum cortisol in response to the $2 \mathrm{mg}$ dexamethasone test (77). A serum cortisol response to insulin-induced hypoglycaemia is usually preserved in depressed patients, whereas this response is blunted in most patients with CS (76). The combined $2 \mathrm{mg}$ dexamethasone-CRH test may be used to differentiate between depression and CS with a reported sensitivity and specificity of $100 \%$ (82). Measurement of midnight circulating cortisol is also helpful to distinguish between CS and abnormalities in cortisol metabolism associated with depression (83). 


\section{Aberrant receptor-mediated CS}

In rare cases, cyclic CS may result from the presence of aberrant adrenal receptors. Two different forms should be considered in the context of the cyclic CS. First, cases of transient hypercortisolism have been reported during pregnancy due to aberrant adrenal LH receptor expression. This has been documented in a woman with ACTH-independent bilateral macronodular adrenal hyperplasia, who experienced symptoms compatible with CS during her four pregnancies (84). Secondly, CS may be 'food dependent' as a result of ectopic expression of receptors for gastric inhibitory polypeptide. This phenomenon has been described in some patients with ACTH-independent bilateral macronodular adrenal hyperplasia or an adrenal adenoma. It is characterized by low fasting serum cortisol levels which increase after food intake (84). In fact, there is no true cyclic nature of cortisol overproduction but only food-induced hypercortisolism. Of note, the low-dose dexamethasone suppression test will be false negative, if performed in the fasting state. Furthermore, a reversed diurnal serum cortisol pattern is commonly found.

\section{Factitious CS}

Several cases have been described in which initial biochemical testing suggested the presence of CS, but in whom periodic hypercortisoluria and/or an erratic combination of serum and urinary cortisol measurements led to a diagnosis of factitious CS (85-89). Some patients intermittently ingested hydrocortisone or cortisone acetate, or added hydrocortisone to their urine specimens. This resulted in largely variable and sometimes strongly elevated serum or urinary cortisol levels. In other cases, self-administration of synthetic glucocorticoids such as prednisone and prednisolone resulted in spuriously elevated urinary cortisol levels. Urinary cortisol is still measured by RIA in many laboratories, and this type of assay shows crossreactivity with synthetic glucocorticoids $(88,89)$. When factitious CS is suspected, specific urinary cortisol measurement using gas chromatography/mass spectrometry enables to distinguish cortisol from synthetic glucocorticoids $(88,89)$. Moreover, endogenous cortisol overproduction due to cyclic $\mathrm{CS}$ is accompanied by elevated urinary levels of cortisol metabolites (85).

\section{Glucocorticoid resistance}

Syndromes of glucocorticoid resistance also need to be considered in the differential diagnosis of cyclic CS, because both disorders can give rise to a discrepancy between clinical and laboratory findings, in particular at initial evaluation. Glucocorticoid resistance varies in severity and this syndrome has been extensively reviewed elsewhere (90). The syndrome is hallmarked by hypercortisolism with a stimulated hypothalamicpituitary-adrenal axis resulting from impaired cortisol action at the cellular level. Patients do not have a typical Cushingoid appearance, but women may have high androgen levels due to ACTH-driven adrenal overproduction. Both, urinary free cortisol excretion and serum cortisol levels are increased. The cortisol circadian rhythm is preserved, as is the cortisol response to insulin-induced hypoglycaemia.

\section{Laboratory studies}

Laboratory findings in cyclic and non-cyclic CS are very similar, except for the temporary character in the former group. Periodic hypokalaemia and/or hyperglycaemia commonly occur among patients with cyclic CS. Furthermore, intermittent leucocytosis may be one of the presenting features (60). Table 3 shows the highest reported plasma ACTH levels and urinary free cortisol excretion in the 65 cases with cyclic CS, stratified according to the underlying cause. Patients with ectopic ACTH production appear to have plasma ACTH levels that are far more higher than patients with Cushing's disease, in line with previous findings (69) but discordant with others (91). Urinary excretion of cortisol in these patients may considerably exceed levels measured in patients with Cushing's disease or adrenal adenoma. In patients with ectopic ACTH secretion, urinary free cortisol levels may be as high as $115000 \mathrm{nmol}$ per $24 \mathrm{~h}$ (53). We recently evaluated a patient with cyclic CS whose 24-h urinary cortisol excretion varied more than 1000-fold, i.e. from 27 to $28000 \mathrm{nmol}$ within 1 week (66). Of note, episodes of hypercortisolism can be followed by a phase of hypocortisolism, sometimes even requiring cortisol substitution (29). Finally, rare laboratory abnormalities can be found in cyclic CS. For example, corticosteroidbinding globulin (CBG) deficiency was found in a patient

Table 3 Laboratory characteristics of 65 patients with cyclic Cushing's syndrome.

\begin{tabular}{|c|c|c|c|c|}
\hline & Overall $^{\mathrm{a}}(n=65)$ & Pituitary $(n=35)$ & Ectopic ACTH $(n=17)$ & Adrenal $(n=7)$ \\
\hline ACTH (pg/ml), median (range) & $140(0-4421)$ & $100(6-942)$ & $260(55-4421)$ & $0\left(0-148^{\mathrm{b}}\right)$ \\
\hline $\begin{array}{l}\text { Urinary free cortisol (nmol/24 h), } \\
\text { median (range) }\end{array}$ & $4810(35-115197)$ & $2147(35-31500)$ & 9655 (2061-115 197) & 998 (535-8195) \\
\hline
\end{tabular}


with cyclic CS (23). Biochemical evaluation showed elevated serum-free cortisol levels with low CBG values, indicating the relevance of serum-free cortisol or salivary cortisol measurements in unusual cases.

Once cyclic CS is suspected, timing of laboratory testing and repeated measurements is essential. Such laboratory evaluation may be done by frequent measurements of 24-h urinary free cortisol excretion. However, incomplete collections may lead to falsely lower cortisol values. To overcome these problems, serial overnight cortisol/creatinine ratios are useful (52). In addition, regular salivary cortisol measurements may also be a valuable tool to demonstrate cyclic CS $(25,26)$. Its strong correlation with free plasma cortisol (92) and urinary free cortisol levels (26) makes it an attractive procedure in diagnosing CS (93).

In patients with cyclic CS, the usefulness of additional endocrine tests, such as the high-dose dexamethasone suppression test and CRH stimulation test to differentiate between pituitary and ectopic ACTH hypersecretion, is questionable. The cortisol response is largely affected by the cyclic cortisol activity. For instance, a dexamethasone suppression test performed during the inclining part of a cycle might disclose that serum cortisol does not suppress or even increases. Indeed, several reports have shown a so-called paradoxical response to dexamethasone $(9,40,52,55)$, which also occurs in primary pigmented nodular adrenocortical disease (94). Conversely, an initial dexamethasone suppression performed just as the elevated steroids are about to fall spontaneously might be falsely interpreted as adequate suppression. Similarly, stimulation tests with $\mathrm{CRH}$ or metyrapon may reveal a blunted response of serum cortisol or plasma ACTH, when carried out in the decremental phase of a cycle, again leading to misdiagnosis.

When ectopic ACTH secretion is suspected, biochemical evaluation of carcinoid tumours should be performed, as these tumours most commonly occur in this situation. These tumours produce biogenic amines, which allow for specific biochemical detection. Platelet serotonin levels and urinary excretion of both serotonin and its metabolite 5-hydroxyindoleacetic acid (5-HIAA) are useful for screening. Measurement of urinary 5-HIAA excretion is widely performed, although its specificity for carcinoid screening is limited (95). Furthermore, urinary 5-HIAA only detects a substantial rise in serotonin metabolism, while foregut carcinoids, such as thymic and bronchial carcinoids, usually have a low serotonin turnover. Platelet serotonin content is not affected by food-derived serotonin, and its measurement allows detecting small increases in serotonin production (96). Another carcinoid marker is urinary serotonin, but this assay is not widely used. Urinary serotonin is derived from circulating free serotonin or it is formed from its circulating precursor 5-hydroxytryptophan (5-HTP) by the enzyme aromatic L-amino acid decarboxylase (AADC) present in renal tubules. Especially in foregut carcinoids, urinary serotonin excretion can be elevated, while platelet serotonin or urinary 5-HIAA is normal. The assumed mechanism is that forgut carcinoids lack AADC, as evidenced by elevated 5-HTP levels in such patients $(97,98)$. Chromogranin A is useful as general neuroendocrine tumour marker in patients with suspected ectopic ACTH secretion. In a recent National Institutes of Health (NIH) series of ectopic CS (91), serum calcitonin was elevated in about $70 \%$ of patients with ectopic ACTH production, including all patients with medullary thyroid cancer. As calcitonin is known to be normal in patients with Cushing's disease and frequently elevated in carcinoids and other neuroendocrine tumours, it may help to discriminate between an ectopic and pituitary source of ACTH hypersecretion.

\section{Diagnostic approach to a patient with possible cyclic CS}

It can be extremely difficult to establish a diagnosis of cyclic CS. Moreover, it should be realized that no definite scheme is available for its diagnosis, and that the laboratory work up for diagnosing and differentiating CS varies between centres. Emphasizing that clinical awareness of the existence of cyclic CS is most important, we propose the following guidelines for the work up of a patient with possible cyclic CS.

Patients with suspected cyclic CS can be distinguished in two distinct clinical categories, each with a specific differential diagnosis and work up.

\section{Category I: clinical suspicion of CS but normal or discrepant biochemical findings}

In case of clinical suspicion of CS, cyclic CS should be considered when initial laboratory results (urinary free cortisol excretion or serum cortisol levels before or after overnight dexamethasone suppression) are abnormal, but when laboratory tests appear to be normal during follow-up or at time of performing differentiation tests. Cyclic CS should also be considered in case of clinical suspicion of CS, but normal initial laboratory results. In these situations, we propose the following differential diagnostic approach:

A) Cyclic CS: repeat measurements of urinary free cortisol and/or salivary cortisol levels during months to years; attempt to establish three peaks and two troughs over time; perform differentiation tests only during phase of cortisol excess.

B) Mild or subclinical CS: repeat laboratory measurements; consider combined dexamethasone-CRH test.

C) Pseudo-Cushing's states: in case of depression or alcohol abuse consider combined insulin tolerance test or dexamethasone-CRH test; in case of alcohol 
abuse, consider repeated testing after period of supervised alcohol abstinence.

D) Aberrant receptor-mediated CS: consider in case of cyclic hormonogenesis with active phase during pregnancy, and in case of discrepant results between urinary free cortisol excretion and $0800 \mathrm{~h}$ fasting serum cortisol after overnight dexamethasone suppression. For these situations, specific stimulation tests are available (84).

\section{Category II: biochemical evidence for cortisol excess but low clinical suspicion of CS}

When initial laboratory findings show cortisol excess, but typical clinical signs of CS are hardly found, cyclic CS may be still present. In these situations, we propose the following differential diagnostic approach:

A) Cyclic CS: see above.

B) Factitious CS: consider when various laboratory results are discrepant; consider using most specific laboratory tests for assessment of hypercortisoluria and endogenous cortisol production; repeat laboratory measurements over time.

C) Glucocorticoid resistance: consider in case of laboratory evidence for cortisol excess but no typical clinical signs and symptoms; consider insulin tolerance test; repeat laboratory measurement to rule out a marked cyclic pattern.

\section{Imaging studies}

Obviously, as in non-cyclic CS, imaging studies should be guided by the results of the biochemical evaluations. If bilateral inferior petrosal sinus sampling is considered to establish a pituitary origin of ACTH production, then the presence of hypercortisolism should be established shortly beforehand. In the absence of concurrent cortisol excess, this procedure should be postponed.

Localization of ectopic ACTH-secreting processes can be difficult, since in about $15 \%$ of patients no underlying tumour is found $(69,91)$. The recommended diagnostic approach in this situation is computed tomography (CT) or magnetic resonance imaging (MRI) scan of neck, chest and abdomen. MRI seems preferable as it may detect bronchial carcinoid tumours overlooked on CT imaging. Importantly, on CT scans of the anterior mediastinum, thymic remnant tissue and small thymic carcinoid tumours can have a similar appearance particularly in young subjects, potentially leading to incorrect diagnosis (99). As most carcinoid tumours and other neuroendocrine tumours express somatostatin receptors, octreotide receptor scintigraphy has been evaluated for localization of ectopic ACTHproducing tumours. However, the sensitivity for tumour detection appears to be only $49 \%$ in a recent $\mathrm{NIH}$ series
(91). Furthermore, with few exceptions, octreotide scintigraphy in general does not disclose tumours unapparent on conventional imaging $(91,100,101)$. If the tumour remains undetected, ${ }^{18}$ fluorodeoxyglucose positron emission tomography (PET) may be useful (102), but its exact diagnostic position has to be still established (103). For detection of carcinoid tumours, PET using the serotonin precursor ${ }^{11} \mathrm{C}-5-\mathrm{HTP}$ is valuable but its availability is limited to a few centres (103). From experience of the $\mathrm{NIH}$ group and others, it has become clear that a single positive imaging study easily leads to a false-positive result, while more than one positive imaging study mostly confirms the presence of a true ectopic ACTHsecreting tumour $(69,91,104)$. This supports the policy to combine different imaging studies.

\section{Treatment}

A detailed overview of the various treatment options for $\mathrm{CS}$ is beyond the scope of this review. For obvious reasons, treatment of cyclic CS is dependent on its cause and is similar to that of patients with sustained hypercortisolism. Thus, neurosurgical treatment, if possible using minimally invasive endoscopic techniques, is the primary therapy for Cushing's disease (16). Pituitary irradiation, which may comprise conventional irradiation or newer techniques employing stereotactic radiosurgery with the $\gamma$-knife or the linear accelerator, is a second treatment option (105). In exceptional cases, bilateral adrenalectomy may be an additional treatment option. Laparoscopic adrenalectomy is warranted in case of unilateral adrenal adenoma, whereas both adrenals should be removed in patients with bilateral (micro)nodular hyperplasia. In case of ectopic ACTH production, removal of the primary process may be more difficult and clearly depends on the exact localization of the ACTHproducing process, usually a carcinoid. Bronchial carcinoids can be treated with video-assisted minithoracotomy or with more invasive procedures if necessary. Other tumours, like a thymic carcinoid, each follow their own specific approach. When extensive imaging studies fail to localize the primary ACTH-producing process, bilateral adrenalectomy may be warranted. In subjects in whom both direct removal of the process responsible for ACTH hypersecretion and bilateral laparoscopic adrenalectomy are not possible or contraindicated medical therapy is required. Several drugs can be used for this, including ketoconazole, aminoglutethimide, metyrapone and mitotane (106). In case of ectopic ACTH syndrome, treatment with somatostatin analogues may be considered for amelioration of ACTH secretion and glucocorticoid excess (107, 108). Such treatment is unlikely to exert an important anti-tumoural effect. The potential benefit of somatostatin receptor-targeted radionuclide therapy for ACTH-producing tumours is not yet clear. 


\section{Conclusions}

Cyclic CS is a rare but well-defined and probably under-reported entity, which poses a greater than usual diagnostic challenge. Clinicians should be aware that hypercortisolism can manifest in a periodic fashion. Cyclic CS can be due to both ACTH-dependent and independent causes, and should be discerned from mild or subclinical CS, pseudo-Cushing's states, aberrant receptor-mediated CS and factitious CS. Since clinical signs can be limited or even absent, it should also be discerned from glucocorticoid resistance syndromes. The pathophysiology of cyclic CS is still poorly understood. As with CS in general, treatment is dependent on its underlying cause. Whether a cyclic pattern of hypercortisolism affects prognosis is unknown.

\section{References}

1 Hellman L, Weitzman ED, Roffwarg H, Fukushima DK \& Yoshida K. Cortisol is secreted episodically in Cushing's syndrome. Journal of Clinical Endocrinology and Metabolism 1970 30 686-689.

2 Krieger DT. Circadian pituitary adrenal rhythms. Advances in Experimental Medicine and Biology 197554 169-189.

3 Curtis GC. Long-term changes in corticosteroid excretion. In Biorhythms and Human Reproduction, pp 417-423. Eds M Ferin, F Halberg, RM Richart \& RL Vande Wiele, New York: John Wiley, 1974.

4 Glass AR, Zavadil AP III, Halberg F, Cornelissen G \& Schaaf M. Circadian rhythm of serum cortisol in Cushing's disease. Journal of Clinical Endocrinology and Metabolism 198459 161-165.

5 Bailey RE. Periodic hormonogenesis-a new phenomenon. Periodicity in function of a hormone-producing tumor in man. Journal of Clinical Endocrinology and Metabolism 197132 317-327.

6 Bassoe HH, Emberland R \& Stoa KF. Fluctuating steroid excretion in Cushing's syndrome. Acta Endocrinologica 195828 163-168.

7 Brooks RV, Jeffcoate SL, London DR, Prunty FT \& Smith PM. Intermittent Cushing's syndrome with anomalous response to dexamethasone. Journal of Endocrinology 196636 53-61.

8 Zondek H, Zondek GW \& Leszynsky HE. Fluctuability of steroid excretion. Acta Endocrinologica 195726 91-95.

9 Brown RD, Van Loon GR, Orth DN \& Liddle GW. Cushing's disease with periodic hormonogenesis: one explanation for paradoxical response to dexamethasone. Journal of Clinical Endocrinology and Metabolism 197336 445-451.

10 Shapiro MS \& Shenkman L. Variable hormonogenesis in Cushing's syndrome. Quarterly Journal of Medicine 199179 351-363.

11 Bochner F, Burke CJ, Lloyd HM \& Nurnberg BI. Intermittent Cushing's disease. American Journal of Medicine 197967 507-510.

12 Hannah J, Lippe B, Lai-Goldman M \& Bhuta S. Oncocytic carcinoid of the kidney associated with periodic Cushing's syndrome. Cancer $1988612136-2140$.

13 Vagnucci AH \& Evans E. Cushing's disease with intermittent hypercortisolism. American Journal of Medicine $1986 \mathbf{8 0} 83-88$.

14 Oates TW, McCourt JP, Friedman WA, Agee OF, Rhoton AL \& Thomas WC Jr. Cushing's disease with cyclic hormonogenesis and diabetes insipidus. Neurosurgery 19795 598-603.

15 Walker AB, Leese GP \& Vora JP. Diagnostic difficulties in periodic Cushing's syndrome. Postgraduate Medical Journal $1997 \mathbf{7 3}$ 426-428.

16 Boscaro M, Barzon L, Fallo F \& Sonino N. Cushing's syndrome. Lancet 2001357 783-791.
17 McCance DR, Gordon DS, Fannin TF, Hadden DR, Kennedy L, Sheridan B \& Atkinson AB. Assessment of endocrine function after transsphenoidal surgery for Cushing's disease. Clinical Endocrinology 199338 79-86.

18 Streeten DH, Anderson GH Jr, Dalakos T \& Joachimpillai AD. Intermittent hypercortisolism: a disorder strikingly prevalent after hypophysial surgical procedures. Endocrine Practice 19973 123-129.

19 Atkinson AB, Kennedy AL, Carson DJ, Hadden DR, Weaver JA \& Sheridan B. Five cases of cyclical Cushing's syndrome. BMJ 1985 291 1453-1457.

20 Carson DJ, Sloan JM, Cleland J, Russell CF, Atkinson AB \& Sheridan B. Cyclical Cushing's syndrome presenting as short stature in a boy with recurrent atrial myxomas and freckled skin pigmentation. Clinical Endocrinology 198828 173-180.

21 Gomez Muguruza MT \& Chrousos GP. Periodic Cushing syndrome in a short boy: usefulness of the ovine corticotropin releasing hormone test. Journal of Pediatrics 1989115 270-273.

22 Sarlis NJ, Chrousos GP, Doppman JL, Carney JA \& Stratakis CA. Primary pigmented nodular adrenocortical disease: reevaluation of a patient with carney complex 27 years after unilateral adrenalectomy. Journal of Clinical Endocrinology and Metabolism 199782 1274-1278.

23 Watanobe H, Nigawara T, Nasushita R, Sasaki S \& Takebe K. A case of cyclical Cushing's disease associated with corticosteroidbinding globulin deficiency: a rare pitfall in the diagnosis of Cushing's disease. European Journal of Endocrinology 1995133 317-319.

24 Atkinson AB, McCance DR, Kennedy L \& Sheridan B. Cyclical Cushing's syndrome first diagnosed after pituitary surgery: a trap for the unwary. Clinical Endocrinology 199236 297-299.

25 Mosnier-Pudar H, Thomopoulos P, Bertagna X, Fournier C. Guiban D \& Luton JP. Long-distance and long-term follow-up of a patient with intermittent Cushing's disease by salivary cortisol measurements. European Journal of Endocrinology 1995133 313-316.

26 Hermus AR, Pieters GF, Borm GF, Verhofstad AA, Smals AG, Benraad TJ \& Kloppenborg PW. Unpredictable hypersecretion of cortisol in Cushing's disease: detection by daily salivary cortisol measurements. Acta Endocrinologica $1993 \mathbf{1 2 8}$ 428-432.

27 Jordan RM, Ramos-Gabatin A, Kendall JW, Gaudette D \& Walls RC. Dynamics of adrenocorticotropin (ACTH) secretion in cyclic Cushing's syndrome: evidence for more than one abnormal ACTH biorhythm. Journal of Clinical Endocrinology and Metabolism $198255531-537$.

28 Schweikert HU, Fehm HL, Fahlbusch R, Martin R, Kolloch R, Higuchi M \& Kruck F. Cyclic Cushing's syndrome combined with cortisol suppressible, dexamethasone non-suppressible ACTH secretion: a new variant of Cushing's syndrome. Acta Endocrinologica $1985110289-295$.

29 Liebowitz G, White A, Hadani M \& Gross DJ. Fluctuating hyperhypocortisolaemia: a variant of Cushing's syndrome. Clinical Endocrinology 199746 759-763.

30 Sakiyama R, Ashcraft MW \& Van Herle AJ. Cyclic Cushing's syndrome. American Journal of Medicine 198477 944-946.

31 Popovic V, Micic D, Nesovic M, Howlett T, Doniach I, Kendereski A, Djordjevic P, Manojlovic D, Micic J \& Besser M. Cushing's disease cycling over ten years. Experimental and Clinical Endocrinology 199096 143-148.

32 De Feo ML, Bonfanti L, Romano S, Fusi S, Giusti G, Messeri G \& Forti G. Cyclical Cushing's disease: report of a case cured by conventional cobaltotherapy. Journal of Endocrinological Investigation 198710 89-93.

33 Schteingart DE \& McKenzie AK. Twelve-hour cycles of adrenocorticotropin and cortisol secretion in Cushing's disease. Journal of Clinical Endocrinology and Metabolism 198051 1195-1198.

34 Cook DM, Kendall JW \& Jordan R. Cushing syndrome: current concepts of diagnosis and therapy. Western Journal of Medicine $1980132111-122$. 
35 Beckers A, Stevenaert A, Pirens G, Flandroy P, Sulon J \& Hennen G. Cyclical Cushing's disease and its successful control under sodium valproate. Journal of Endocrinological Investigation 199013 923-929.

36 Adachi M, Takayanagi R, Yanase T, Sakai Y, Ikuyama S, Nakagaki H, Osamura Y, Sanno N \& Nawata H. Cyclic Cushing's disease in long-term remission with a daily low dose of bromocriptine. Internal Medicine 199635 207-211.

37 Yamaguchi K \& Hashiguchi Y. A significant adverse correlation between serum cortisol and TSH in a case of cyclic Cushing's disease based on a continuous three-year observation. Endocrine Journal $2003 \mathbf{5 0} 833-834$.

38 Hashimoto K, Kaneda T, Nagano I, Asaba K, Takeda K \& Takao T. Pituitary adenoma showing intermittent secretion of high molecular weight adrenocorticotropin without evidence of Cushing's disease. Hormone Research 199952 39-44.

39 Loh KC. Cyclical Cushing's syndrome-a trap for the unwary. Singapore Medical Journal 199940 321-324.

40 Liberman B, Wajchenberg BL, Tambascia MA \& Mesquita $\mathrm{CH}$. Periodic remission in Cushing's disease with paradoxical dexamethasone response: an expression of periodic hormonogenesis. Journal of Clinical Endocrinology and Metabolism $1976 \mathbf{4 3}$ 913-918.

41 Velkeniers B, Beckers A, Stevenaert A, Smits J, Finne E \& Vanhaelst L. Cyclical Cushing's disease. A case report. Pathology, Research and Practice $1991 \mathbf{1 8 7}$ 603-607.

42 Hsu TH, Gann DS, Tsan KW \& Russell RP. Cyproheptadine in the control of Cushing's disease. Johns Hopkins Medical Journal 1981 $14977-83$.

43 Mercado-Asis LB, Murayama M, Yamakita N, Morita H, Mune T, Yasuda K \& Miura K. Cortisol-suppressible dexamethasonenonsuppressible cyclic Cushing's disease with evidence of clinical and biochemical remission with bromocriptine. Endocrinologia Japonica 199138 315-324.

44 La Civita KA, McDonald S \& Jacobson J. Cyclic Cushing's disease in association with a pituitary stone. Southern Medical Journal 198982 1174-1176.

45 Peri A, Bemporad D, Parenti G, Luciani P, Serio M \& Mannelli M. Cushing's syndrome due to intermittent ectopic ACTH production showing a temporary remission during a pulmonary infection. European Journal of Endocrinology 2001145 605-611.

46 Arnaldi G, Mancini T, Kola B, Appolloni G, Freddi S, Concettoni C, Bearzi I, Masini A, Boscaro M \& Mantero F. Cyclical Cushing's syndrome in a patient with a bronchial neuroendocrine tumor (typical carcinoid) expressing ghrelin and growth hormone secretagogue receptors. Journal of Clinical Endocrinology and Metabolism $2003 \mathbf{8 8} 5834-5840$.

47 Silva F, Vazquez-Selles J, Aguilo F, Vazquez G \& Flores C. Recurrent ectopic adrenocorticotropic hormone producing thymic carcinoid detected with octreotide imaging. Clinical Nuclear Medicine 199924 109-110.

48 Gartner LA \& Voorhess ML. Adrenocorticotropic hormoneproducing thymic carcinoid in a teenager. Cancer $1993 \mathbf{7 1}$ 106-111.

49 Findling JW, Buggy BP, Segerson TP \& Raff H. Pneumocystis carinii pneumonia complicating intermittent Cushing's syndrome. Wisconsin Medical Journal 198685 23-25.

50 Scott RS, Espiner EA \& Donald RA. Intermittent Cushing's disease with spontaneous remission. Clinical Endocrinology 197911 561-566.

51 van Coevorden A, Laurent E, Rickaert F, van Reeth O, Van Cauter E \& Mockel J. Cushing's syndrome with intermittent ectopic ACTH production. Journal of Endocrinological Investigation 199013 317-326.

52 Stewart PM, Venn P, Heath DA \& Holder G. Cyclical Cushing's syndrome. British Journal of Hospital Medicine 199248 186-187.

53 Thorner MO, Martin WH, Ragan GE, Macleod RM, Feldman PS, Bruni C \& Williamson BR. A case of ectopic ACTH syndrome: diagnostic difficulties caused by intermittent hormone secretion. Acta Endocrinologica 198299 364-370.
54 Estopinan V, Varela C, Riobo P, Dominguez JR \& Sancho J. Ectopic Cushing's syndrome with periodic hormonogenesis-a case suggesting a pathogenetic mechanism. Postgraduate Medical Journal 198763 887-889.

55 Chajek T \& Romanoff $\mathrm{H}$. Cushing syndrome with cyclical edema and periodic secretion of corticosteroids. Archives of Internal Medicine 1976136 441-443.

56 Hirata Y, Yoshimi H, Matsukura S \& Imura H. Effect of hypothalamic extract and other factors on release of adrenocorticotropin from and adenosine 3',5'-monophosphate levels in dispersed nonpituitary tumor cells. Journal of Clinical Endocrinology and Metabolism 197949 317-321.

57 Terzolo M, Ali A, Pia A, Bollito E, Reimondo G, Paccotti P, Scardapane R \& Angeli A. Cyclic Cushing's syndrome due to ectopic ACTH secretion by an adrenal pheochromocytoma. Journal of Endocrinological Investigation 199417 869-874.

58 Hirata Y, Sakamoto N, Yamamoto H, Matsukura S, Imura H \& Okada S. Gastric carcinoid with ectopic production of ACTH and beta-MSH. Cancer 197637 377-385.

59 Gunther DF, Bourdeau I, Matyakhina L, Cassarino D, Kleiner DE, Griffin K, Courkoutsakis N, Abu-Asab M, Tsokos M, Keil M, Carney JA \& Stratakis CA. Cyclical Cushing syndrome presenting in infancy: an early form of primary pigmented nodular adrenocortical disease, or a new entity? Journal of Clinical Endocrinology and Metabolism 200489 3173-3182.

60 Wickus GG, Pagliara AS \& Caplan RH. Spurious elevation of plasma immunoreactive adrenocorticotropic hormone in cyclic Cushing's syndrome. Archives of Pathology and Laboratory Medicine 1989113 797-799.

61 Green JR \& van't Hoff W. Cushing's syndrome with fluctuation due to adrenal adenoma. Journal of Clinical Endocrinology and Metabolism 197541 235-240.

62 Kathol RG, Delahunt JW \& Hannah L. Transition from bipolar affective disorder to intermittent Cushing's syndrome: case report. Journal of Clinical Psychiatry $1985 \mathbf{4 6}$ 194-196.

63 Smith DJ, Kohler PC, Helminiak R \& Carroll J. Intermittent Cushing's syndrome with an empty sella turcica. Archives of Internal Medicine 1982142 2185-2187.

64 Sato T, Uchigata Y, Uwadana N, Kita K, Suzuki Y \& Hayashi S. A syndrome of periodic adrenocorticotropin and vasopressin discharge. Journal of Clinical Endocrinology and Metabolism 1982 $54517-522$.

65 Sato T, Funahashi T, Mukai M, Uchigata Y, Okuda N, Ichizen T \& Periodic ACTH. Periodic ACTH discharge. Journal of Pediatrics $198097221-225$.

66 Meinardi JR, van den Berg G, Wolffenbuttel BHR, Kema IP \& Dullaart RPF. Cyclical Cushing's syndrome due to an atypical thymic carcinoid. Netherlands Journal of Medicine $2006 \mathbf{6 4} 23-27$.

67 Mantero F, Scaroni CM \& Albiger NM. Cyclic Cushing's syndrome: an overview. Pituitary 20047 203-207.

68 Orth DN. Cushing's syndrome. New England Journal of Medicine 1995332 791-803.

69 Wajchenberg BL, Mendonca BB, Liberman B, Pereira MA, Carneiro PC, Wakamatsu A \& Kirschner MA. Ectopic adrenocorticotropic hormone syndrome. Endocrine Reviews 199415 $752-787$

70 Isidori AM, Kaltsas GA, Pozza C, Frajese V, Newell-Price J, Reznek RH, Jenkins PJ, Monson JP, Grossman AB \& Besser GM. The ectopic adrenocorticotropin syndrome: clinical features, diagnosis, management, and long-term follow-up. Journal of Clinical Endocrinology and Metabolism 200691 371-377.

71 Robyn JA, Koch CA, Montalto J, Yong A, Warne GL \& Batch JA. Cushing's syndrome in childhood and adolescence. Journal of Paediatrics and Child Health 199733 522-527.

72 Yasuda K. Cyclic Cushing's disease: pitfalls in the diagnosis and problems with the pathogenesis. Internal Medicine 199635 $169-170$.

73 Watanobe H, Aoki R, Takebe K, Nakazono M \& Kudo M. In vivo and in vitro studies in a patient with cyclical Cushing's disease showing some responsiveness to bromocriptine. Hormone Research $199136227-234$. 
74 Scapagnini U, Van Loon GR, Moberg GP, Preziosi P \& Ganong WF. Evidence for central norepinephrine-mediated inhibition of ACTH secretion in the rat. Neuroendocrinology 197210 155-160.

75 Lightman SL \& Forsling M. Evidence for dopamine as an inhibitor of vasoprotein release in man. Clinical Endocrinology 198012 $39-46$.

76 Arnaldi G, Angeli A, Atkinson AB, Bertagna X, Cavagnini F, Chrousos GP, Fava GA, Findling JW, Gaillard RC, Grossman AB, Kola B, Lacroix A, Mancini T, Mantero F, Newell-Price J, Nieman LK, Sonino N, Vance ML, Giustina A \& Boscaro M. Diagnosis and complications of Cushing's syndrome: a consensus statement. Journal of Clinical Endocrinology and Metabolism 2003 88 5593-5602.

77 Newell-Price J, Trainer P, Besser M \& Grossman A. The diagnosis and differential diagnosis of Cushing's syndrome and pseudoCushing's states. Endocrine Reviews 199819 647-672.

78 Yanovski JA, Cutler GB Jr, Chrousos GP \& Nieman LK. The dexamethasone-suppressed corticotropin-releasing hormone stimulation test differentiates mild Cushing's disease from normal physiology. Journal of Clinical Endocrinology and Metabolism 1998 83 348-352.

79 Rossi R, Tauchmanova L, Luciano A, Di Martino M, Battista C, Del Viscovo L, Nuzzo V \& Lombardi G. Subclinical Cushing's syndrome in patients with adrenal incidentaloma: clinical and biochemical features. Journal of Clinical Endocrinology and Metabolism 200085 1440-1448.

80 Terzolo M, Bovio S, Reimondo G, Pia A, Osella G, Borretta G \& Angeli A. Subclinical Cushing's syndrome in adrenal incidentalomas. Endocrinology and Metabolism Clinics of North America 200534 423-439.

81 Reincke M. Subclinical Cushing's syndrome. Endocrinology and Metabolism Clinics of North America 200029 43-56.

82 Yanovski JA, Cutler GB Jr, Chrousos GP \& Nieman LK. Corticotropin-releasing hormone stimulation following lowdose dexamethasone administration. A new test to distinguish Cushing's syndrome from pseudo-Cushing's states. JAMA 1993 $2692232-2238$.

83 Papanicolaou DA, Yanovski JA, Cutler GB Jr, Chrousos GP \& Nieman LK. A single midnight serum cortisol measurement distinguishes Cushing's syndrome from pseudo-Cushing states. Journal of Clinical Endocrinology and Metabolism $1998 \mathbf{8 3}$ 1163-1167.

84 Lacroix A, Ndiaye N, Tremblay J \& Hamet P. Ectopic and abnormal hormone receptors in adrenal Cushing's syndrome. Endocrine Reviews 200122 75-110.

85 Cook DM \& Meikle AW. Factitious Cushing's syndrome. Journal of Clinical Endocrinology and Metabolism 198561 385-387.

86 O'Hare JP, Vale JA, Wood S \& Corrall RJ. Factitious Cushing's syndrome. Acta Endocrinologica 1986111 165-167.

87 Workman RJ, Nicholson WE \& McCammon DK. Factitious hypercortisoluria. Journal of Clinical Endocrinology and Metabolism 199580 3050-3051.

88 Cizza G, Nieman LK, Doppman JL, Passaro MD, Czerwiec FS, Chrousos GP \& Cutler GB Jr. Factitious Cushing syndrome. Journal of Clinical Endocrinology and Metabolism 199681 3573-3577.

89 Kerstens MN, Hoogenberg K, Kema IP, Minkema HJ \& Dullaart RP. Elevated hormone levels without endocrinopathy: hypercortisoluria and hypoglycemia as facticious disorders. Nederlands Tijdschrift voor Geneeskunde 2001145 609-612.

90 Malchoff CD \& Malchoff DM. Glucocorticoid resistance and hypersensitivity. Endocrinology and Metabolism Clinics of North America 200534 315-326.

91 Ilias I, Torpy DJ, Pacak K, Mullen N, Wesley RA \& Nieman LK. Cushing's syndrome due to ectopic corticotropin secretion: twenty years' experience at the National Institutes of Health. Journal of Clinical Endocrinology and Metabolism 200590 4955-4962.

92 Vining RF, McGinley RA, Maksvytis JJ \& Ho KY. Salivary cortisol: a better measure of adrenal cortical function than serum cortisol. Annals of Clinical Biochemistry 198320 (Pt 6) 329-335.
93 Yaneva M, Mosnier-Pudar H, Dugue MA, Grabar S, Fulla Y \& Bertagna X. Midnight salivary cortisol for the initial diagnosis of Cushing's syndrome of various causes. Journal of Clinical Endocrinology and Metabolism 200489 3345-3351.

94 Stratakis CA, Sarlis N, Kirschner LS, Carney JA, Doppman JL, Nieman LK, Chrousos GP \& Papanicolaou DA. Paradoxical response to dexamethasone in the diagnosis of primary pigmented nodular adrenocortical disease. Annals of Internal Medicine 1999131 585-591.

95 Kema IP, Schellings AM, Meiborg G, Hoppenbrouwers CJ \& Muskiet FA. Influence of a serotonin- and dopamine-rich diet on platelet serotonin content and urinary excretion of biogenic amines and their metabolites. Clinical Chemistry 199238 1730-1736.

96 Kema IP, de Vries EG, Schellings AM, Postmus PE \& Muskiet FA. Improved diagnosis of carcinoid tumors by measurement of platelet serotonin. Clinical Chemistry 199238 534-540.

97 Oates JA \& Sjoerdsma A. A unique syndrome associated with secretion of 5-hydroxytryptophan by metastatic gastric carcinoids. American Journal of Medicine 196232 333-342.

98 Campbell AC, Gowenlock AH, Platt DS \& Snow PJ. A betahydroxytryptophan-secreting carcinoid tumour. Gut 1963 4 61-67.

99 Hanson JA, Sohaib SA, Newell-Price J, Islam N, Monson JP, Trainer PJ, Grossman A, Besser GM \& Reznek RH. Computed tomography appearance of the thymus and anterior mediastinum in active Cushing's syndrome. Journal of Clinical Endocrinology and Metabolism $1999 \mathbf{8 4} 602-605$.

100 de Herder WW, Krenning EP, Malchoff CD, Hofland LJ, Reubi JC, Kwekkeboom DJ, Oei HY, Pols HA, Bruining HA \& Nobels FR. Somatostatin receptor scintigraphy: its value in tumor localization in patients with Cushing's syndrome caused by ectopic corticotropin or corticotropin-releasing hormone secretion. American Journal of Medicine 199496 305-312.

101 Lamberts SW, de Herder WW, Krenning EP \& Reubi JC. A role of (labeled) somatostatin analogs in the differential diagnosis and treatment of Cushing's syndrome. Journal of Clinical Endocrinology and Metabolism 1994 78 17-19.

102 Kumar J, Spring M, Carrol PV, Barrington SF \& Powrie JK. 18Flurodeoxyglucose positron emission tomography in the localization of ectopic ACTH-secreting neuroendocrine tumours. Clinical Endocrinology 200664 371-374.

103 Pacak K, Eisenhofer G \& Goldstein DS. Functional imaging of endocrine tumors: role of positron emission tomography. Endocrine Reviews 200425 568-580.

104 Pacak K, Ilias I, Chen CC, Carrasquillo JA, Whatley M \& Nieman LK. The role of [(18)F]fluorodeoxyglucose positron emission tomography and [(111)In]-diethylenetriaminepentaacetate-D-Phe-pentetreotide scintigraphy in the localization of ectopic adrenocorticotropin-secreting tumors causing Cushing's syndrome. Journal of Clinical Endocrinology and Metabolism 2004 $892214-2221$.

105 Estrada J, Boronat M, Mielgo M, Magallon R, Millan I, Diez S, Lucas T \& Barcelo B. The long-term outcome of pituitary irradiation after unsuccessful transsphenoidal surgery in Cushing's disease. New England Journal of Medicine 1997336 $172-177$.

106 Nieman LK. Medical therapy of Cushing's disease. Pituitary 2002 5 77-82.

107 de Herder WW \& Lamberts SW. Is there a role for somatostatin and its analogs in Cushing's syndrome? Metabolism 199645 $83-85$.

108 von Werder K, Muller OA \& Stalla GK. Somatostatin analogs in ectopic corticotropin production? Metabolism $1996 \mathbf{4 5}$ 129-131.

Received 19 April 2007

Accepted 18 June 2007 